\title{
STUDIES ON A PROTEOLYTIC ENZYME IN HUMAN PLASMA. IX. FIBRINOGEN AND FIBRIN AS SUBSTRATES FOR THE PROTEOLYTIC ENZYME OF PLASMA ${ }^{1}$
}

\author{
By OSCAR D. RATNOFF with the TEChNICAL ASSISTANCE OF JOAN COLOPY
}

\author{
(From the Department of Medicine, the Western Reserve University School of Medicine, \\ and University Hospitals, Cleveland, Ohio)
}

(Submitted for publication December 11, 1952; accepted February 19, 1953)

In a careful study of the properties of the proteolytic enzyme of plasma which is active near neutrality, Christensen (1) reported that preparations of this substance digested fibrinogen and fibrin with equal avidity. This observation has been challenged by Fantl, Simon, and Fitzpatrick $(2,3)$ who claimed that fibrin is a more suitable substrate for this enzyme than fibrinogen.

The experiments to be described were undertaken to investigate these two divergent views. The problem to be resolved necessitated a com. parison between the time required for the digestion of two different proteins, fibrinogen and fibrin. Fantl and his associates $(2,3)$ measured the digestion of fibrin by observing the time required for the lysis of the fibrin clot. They studied the digestion of fibrinogen by measuring the amount of this protein which was clotted by thrombin or calcium after an appropriate period of incubation. Under the conditions of their experiments, these workers observed that the fibrin clot was liquefied at a time when appreciable amounts of coagulable fibrinogen remained in the unclotted control mixtures.

In Christensen's experiments, the rate of proteolysis of fibrinogen and of fibrin was determined by measuring the amount of nitrogen in the precipitate which formed upon the addition of trichloracetic acid (1). With this method it was not feasible to determine the rate of digestion of fibrin until lysis of the clot had occurred, but thereafter fibrinolysis and fibrinogenolysis appeared to proceed at the same rate.

A precise study comparing the rates of digestion of two different substrates would require a careful determination of initial reaction velocities. In a

1 This study was supported in part by a grant from the Cleveland Area Heart Society and in part by a research grant (P. H. S. No. G3619) from the National Institutes of Health of the U. S. Public Health Service. heterogeneous system such as the problem at hand requires, this type of analysis is attended with many theoretic difficulties. Nonetheless, it was possible to obtain data which appeared to explain the discrepancy between the experiments of Christensen and of Fantl, Simon, and Fitzpatrick. The proteolytic enzyme system in plasma is ordinarily inactive. Treatment of the plasma with chloroform or with streptokinase, a filterable principle which appears in cultures of certain beta hemolytic streptococci, results in activation of this enzyme $(1,4)$. When streptokinase was added to human plasma, a fibrin clot was dissolved in a shorter time than was required for the disappearance of coagulable fibrinogen, as Fantl had reported. On the other hand, active plasma proteolytic enzyme digested fibrinogen to the point at which it was incoagulable in the same time that an equal amount of fibrin was dissolved. This suggested that Christensen's observation was valid, that the plasma enzyme digested fibrinogen and fibrin at the same rate, and that the experiments of Fantl and his associates indicated that the activation of the proteolytic enzyme from its precursor was more rapid in the presence of a fibrin clot than in a solution of fibrinogen.

\section{METHOD}

Nomenclature. The term plasma proteolytic enzyme will be used to denote the substance or substances in plasma which can digest fibrinogen, fibrin and certain other proteins in vitro at or near neutrality. This enzyme has also been named plasmin (5) and fibrinolysin (6). It is usually present in plasma as an inactive precursor. The filterable principle of cultures of hemolytic streptococci which activates the precursor will be called streptokinase (5). The term enzyme is intended to imply neither a purified product nor even a single substance. The term fibrinogen designates the component of plasma which forms a clot of fibrin upon the addition of thrombin.

Preparation of buffer. The buffer used was $0.025 \mathrm{M}$ barbital and $0.125 \mathrm{M}$ sodium chloride, at $\mathrm{pH}$ 7.5. This 
buffer was prepared by dissolving $7.30 \mathrm{gm}$. of sodium chloride, $2.76 \mathrm{gm}$. of barbital and $2.06 \mathrm{gm}$. of sodium barbital in 1 liter of water.

Preparation of fibrinogen. Human fibrinogen was prepared by a modification of Holmberg's method (7) described earlier (8). About 85 per cent of the protein in this preparation was coagulable. Bovine fibrinogen, ${ }^{2}$ prepared by the method of Ware, Guest, and Seegers (9), was dissolved in buffer and the undissolved residue was separated by filtration through Whatman No. 1 filter paper. In all experiments, a portion of dried fibrinogen weighing $100 \mathrm{mg}$. was dissolved in $20 \mathrm{ml}$. of buffer. This preparation contained $0.9 \mathrm{gm}$. of sodium chloride for every $3.1 \mathrm{gm}$. of protein. Assay of the filtrate demonstrated approximately $300 \mathrm{mg}$. of coagulable protein per $100 \mathrm{ml}$. of solution. There was a variation of as much as $50 \mathrm{mg}$. of coagulable protein per $100 \mathrm{ml}$. from preparation to preparation, but this did not influence the results obtained. In any given experiment, the same solution of fibrinogen was used throughout.

Preparation of bovine plasma proteolytic enzyme. Bovine plasma proteolytic enzyme, ${ }^{3}$ prepared by the method of Loomis, George and Ryder (6), was dissolved in buffer in a concentration of 10 units per $\mathrm{ml}$. and stored at $-10^{\circ} \mathrm{C}$. until use. This enzyme has been activated by treatment with chloroform. The preparation used contained 0.82 Loomis units per $\mathrm{mg}$.

Preparation of thrombin. Commercial bovine thrombin 4 was dissolved in buffer in a concentration of 1000 National Institutes of Health (N. I. H.) units per ml. (10), and stored at $-10^{\circ}$ C. until use. More highly purified bovine thrombin 4 did not differ in its effect from the commercial product. Both preparations possessed appreciable inhibitory activity against the plasma proteolytic enzyme.

Preparation of streptokinase. A lyophilized preparation of streptokinase ${ }^{5}$ was dissolved in buffer and stored at $-10^{\circ} \mathrm{C}$. This preparation contained 53 units of streptococcal desoxyribonuclease for each 169 units of streptokinase. Furthermore, it possessed inhibitory activity either against the streptokinase itself, or the proteolytic enzyme, easily demonstrable in higher concentrations of the material. Critical experiments were confirmed by the use of highly purified streptokinase containing 36 units of activity per microgram (11) obtained from Dr. L. R. Christensen of New York.

Preparation of oxalated plasma. Blood from nonfasting adult subjects was mixed with dried oxalate salts in a proportion of $5 \mathrm{ml}$. of blood to $6 \mathrm{mg}$. of ammonium

\footnotetext{
2 Bovine fibrinogen was obtained through the courtesy of Dr. Walter Seegers.

${ }^{8}$ Bovine plasma proteolytic enzyme (fibrinolysin) was obtained through the courtesy of Parke, Davis and Company, Detroit, Mich.

\& Obtained through the courtesy of Parke, Davis and Company, Detroit, Mich.

Streptokinase was obtained through the courtesy of Lederle Laboratories, Pearl River, N. Y.
}

oxalate and $4 \mathrm{mg}$. of potassium oxalate. The plasma was then separated by centrifugation at $2,000 \mathrm{rpm}$ for $15 \mathrm{~min}$ utes in an International centrifuge, Model SBV Size 1.

Preparation of oxalated serum. Human blood was allowed to clot, and then $0.1 \mathrm{M}$ sodium oxalate solution was added in a ratio of $0.5 \mathrm{ml}$. of oxalate to $4.5 \mathrm{ml}$. of blood. The mixture was centrifuged for 15 minutes at 2,000 rpm and the oxalated serum was then incubated at $37^{\circ} \mathrm{C}$. for 30 minutes, to allow any free thrombin to deteriorate. The serum was oxalated since the addition of fibrinogen to serum was followed by clotting in the presence of calcium ions. No clotting occurred when fibrinogen was added to the oxalated serum, and for this reason it was assumed that no appreciable amount of thrombin remained.

Preparation of platelet-deficient plasma. Plateletdeficient plasma was prepared by the method of Conley, Hartmann, Morse and Lalley $(12,13)$, using siliconecoated glassware and needles boiled with arquad $2 \mathrm{C.}^{6}$

Preparation of precursor. A crude preparation of the precursor of the plasma proteolytic enzyme was made by diluting oxalated plasma with 19 volumes of water and acidifying to $\mathrm{pH} 5.2$ with 1 per cent acetic acid. The precipitated globulin was separated by centrifugation and dissolved in buffer, usually in a volume equal to that of the original plasma.

Measurement of proteolysis. The time required for the liquefaction of a fibrin clot was measured by direct observation of the clot. Many of the experiments were made with plasma. Since plasma contains other substrates than fibrin, it was not suitable to measure the increase in non-protein nitrogen which may have occurred pari passu with fibrinolysis, and indeed, in the absence of fibrin free of other proteins, the measurement of nonprotein digestion products is never beyond criticism. In all experiments, the clot lysis time was measured from the time that the reagents were mixed rather than from the time of clotting. This was a matter of convenience, because the clotting time was usually short compared to the clot lysis time, and did not influence the recorded results. Care was taken to avoid disturbing the clot during the period of observation. If the clot was agitated, retraction appeared to occur, and it became difficult to estimate the clot lysis time.

The time required for the digestion of fibrinogen was measured by determining the amount of fibrinogen which remained in the preparation at appropriate intervals. The amount of fibrinogen which was present was estimated indirectly by measuring the clotting time upon the addition of thrombin. This assay depended upon the fact that the clotting time of a mixture of fibrinogen and thrombin increases as the concentration of fibrinogen decreases (14). As fibrinogen was digested, the clotting time upon the addition of thrombin was prolonged. The concentration of fibrinogen can be estimated only grossly by this method. When the addition of thrombin did not result in a clot, it was assumed that no appreciable amount of

${ }^{6}$ Arquad 2C was obtained through the courtesy of Armour and Company, Chicago, Ill. 
fibrinogen was present. Under certain conditions, fibrinolysis can occur so rapidly after the addition of thrombin to fibrinogen, that a clot cannot be seen. Under these conditions, the presence of fibrinogen cannot be detected by this method. However, this possible source of error could not have been a factor under the conditions of the experiments to be described.

The time required for the digestion of fibrin to the point at which the clot was liquefied was compared, in these experiments, with the time required for the digestion of fibrinogen to the point at which it became incoagulable. To make this comparison, appropriate amounts of the preparation to be tested were pipetted into each of a series of tubes. Thrombin was added to one of the tubes and an equal amount of buffer to the others. The mixtures were then incubated at $37^{\circ} \mathrm{C}$. The clot lysis time of the tube containing thrombin was measured. At intervals, thrombin was added to successive tubes and the clotting times noted. The amount of fibrinogen which remained undigested was estimated from the clotting time, in the manner described. Variations in this basic technique will be mentioned in relation to the individual experiments reported.

In all experiments, the reagents were mixed in tubes which were immersed in an ice-bath, and the tubes were then transferred simultaneously to a water bath at $37^{\circ} \mathrm{C}$. When the progress of digestion was observed for a period longer than two or three hours, a drop of toluene was added to each tube as a bacteriostatic agent, and the tubes were closed with rubber stoppers. Unless otherwise noted, the experiments were performed in pyrex tubes, with an internal diameter of $8 \mathrm{~mm}$. When siliconecoated glassware was used, it was prepared by the application of at least three coats of Desicote (Beckmann). The data presented in the tables are representative of repeated experiments.

\section{RESULTS}

(1) The time required for the digestion of fibrinogen and fibrin by bovine proteolytic enzyme

The relative effects of active bovine plasma proteolytic enzyme upon fibrinogen and fibrin was

TABLE I

The relative effect of bovine plasma proteolytic enzyme upon fibrinogen and fibrin

Time required for digestion of (a) fibrin, in a mixture of $0.1 \mathrm{ml}$. bovine thrombin (10 N.I.H. units per ml.) $0.1 \mathrm{ml}$. bovine plasma proteolytic enzyme and $0.3 \mathrm{ml}$. bovine fibrinogen solution, and (b) fibrinogen, in the same mixture, with $0.1 \mathrm{ml}$. buffer substituted for thrombin.

\begin{tabular}{lcc}
\hline \hline & \multicolumn{2}{c}{$\begin{array}{c}\text { Final concentration of plasma } \\
\text { proteclytic ensyme }\end{array}$} \\
\cline { 2 - 3 } Substrate & 1 unit/ml. & 2 units/ml. \\
\hline Fibrin & Time for digestion in minutes \\
Fibrinogen & $13 \frac{1}{2}$ & 6 \\
\hline
\end{tabular}

TABLE II

The relative effect of streptokinase upon the digestion of fibrinogen and fibrin in human plasma

Time required for digestion of (a) fibrin, in a mixture of $0.1 \mathrm{ml}$. bovine thrombin (10 N.I.H. units per ml.), $0.1 \mathrm{ml}$. streptokinase and $0.3 \mathrm{ml}$. oxalated plasma, and (b) fibrinogen, in the same mixture, with $0.1 \mathrm{ml}$. buffer substituted for thrombin.

\begin{tabular}{lcc}
\hline \hline & \multicolumn{2}{c}{ Final concentration of streptokinase } \\
\cline { 2 - 3 } Substrate & 125 units/ml. & 250 units/ml. \\
\hline Fibrin & Time for digestion in minutes \\
Fibrinogen & $1 \frac{1}{\frac{1}{2}}$ & 2 \\
& $20^{2}$ & 8 \\
\hline
\end{tabular}

measured in an homologous system (Table I). In repeated experiments, this enzyme digested fibrinogen to the point at which it was incoagulable in the same time or slightly faster than it liquefied fibrin. The thrombin used to form fibrin possessed inhibitory activity against the proteolytic enzyme and may have prolonged the time required for the digestion of fibrin. In some experiments, when the concentration of the enzyme was low, 4 or 5 per cent of coagulable protein remained at a time when all the fibrin had disappeared. The same results were obtained when human fibrinogen and fibrin were used in place of bovine. Under these conditions, then, no appreciable difference was found between the time required for active bovine plasma proteolytic enzyme to liquefy fibrin and to render fibrinogen incoagulable.

(2) The time required for the digestion of fibrinogen and fibrin by streptokinase-activated proteolytic enzyme in human plasma

Purified streptokinase was mixed with fresh oxalated human plasma and the time required for the digestion of fibrinogen by this mixture was determined immediately. Illustrative data from part of one such experiment are given in Table II. In each of several experiments, appreciable quantities of fibrinogen remained at a time when all the fibrin had been destroyed.

These data are similar to those reported by Fantl and Fitzpatrick (3). It was clear, then, that the experiments upon which these authors based their view that fibrin was digested more rapidly than fibrinogen were readily reproducible. However, when streptokinase is added to plasma, the net effect of at least two consecutive steps is measured, namely, the rate at which the proteo- 
lytic enzyme of plasma is activated by streptokinase, and the rate at which the active enzyme digests the two proteins. If active human plasma proteolytic enzyme, like bovine enzyme, rendered fibrinogen incoagulable in the same time that it liquefied fibrin, one might infer that the activation of plasma proteolytic enzyme by streptokinase occurred more rapidly or completely in the presence of fibrin than in the presence of fibrinogen.

For this reason, active human plasma proteolytic enzyme was tested against the two substrates. A crude preparation of precursor, when activated by streptokinase, again digested fibrin more readily than fibrinogen. The same was true of a solution of Fraction II-III (Cohn) ${ }^{7}$ activated by streptokinase. A more active preparation of enzyme was made by treating precursor successively with chloroform and streptokinase.

In one such experiment, a volume of $12 \mathrm{ml}$. of fresh oxalated plasma was diluted with water and acidified in the manner described. The precipitate was separated by centrifugation, dissolved in $3 \mathrm{ml}$. of buffer, and $0.5 \mathrm{ml}$. aliquots were pipetted into each of six $40 \mathrm{ml}$. round-bottomed centrifuge tubes. The globulin solution in each tube was mixed with an equal volume of chloroform, incubated at $25^{\circ} \mathrm{C}$. overnight, and the globulin was then separated from the chloroform by centrifugation and aeration of the supernatant fluid. The globulin was pooled, diluted with buffer to the original plasma volume, and mixed with a solution of streptokinase containing 625 units per $\mathrm{ml}$. (an amount which activated this particular preparation maximally). This mixture was incubated at $25^{\circ}$ C. for 10 minutes, placed in an ice bath, and serially diluted with buffer. This preparation, then, was plasma proteolytic enzyme activated both by chloroform and streptokinase. The time required for each dilution of enzyme to digest fibrinogen and fibrin was then measured.

Human plasma proteolytic enzyme activated in this way by streptokinase and chloroform digested bovine fibrinogen and fibrin in approximately the same time (Table III). When the concentration of enzyme was low, about 5 per cent of coagulable fibrinogen remained at a time when the fibrin was completely lysed. Thus human plasma proteo-

\footnotetext{
${ }^{7}$ Human plasma fraction II-III was obtained through the courtesy of Dr. E. J. Cohn.
}

TABLE III

The relative effect of chloroform-activated and streptokinaseactioated proteolytic enzyme upon fibrinogen and fibrin

Time required for digestion of (a) fibrin, in a mixture of $0.1 \mathrm{ml}$. bovine thrombin (10 N.I.H. units per $\mathrm{ml}$.), $0.1 \mathrm{ml}$. of chloroform-activated and streptokinase-activated human plasma proteolytic enzyme and $0.3 \mathrm{ml}$. bovine fibrinogen solution, and (b) fibrinogen, in the same mixture, with $0.1 \mathrm{ml}$. buffer substituted for thrombin.

\begin{tabular}{lccccc}
\hline \hline & \multicolumn{5}{c}{ Concentration of ensyme } \\
\cline { 2 - 6 } Substrate & Undiluted & $50 \%$ & $25 \%$ & $12.5 \%$ & $6.25 \%$ \\
\hline \multirow{2}{*}{ Fibrin } & 5 & Time for digestion in minutes \\
Fibrinogen & 5 & 5 & 6 & 7 & 9 \\
& & 5 & 6 & 8 & $10^{*}$
\end{tabular}

*At 10 minutes, about $4 \%$ of the fibrinogen remained undigested.

lytic enzyme behaved in the same manner as bovine. It seemed evident, therefore, that the difference in behavior of mixtures of streptokinase and plasma towards fibrinogen and fibrin was due to a difference in the rate or extent of activation of the proteolytic enzyme in unclotted and clotted plasma. In this experiment, no attempt was made to remove prothrombin from the enzyme preparation. However, enzyme prepared from plasma from which prothrombin had been adsorbed by barium sulfate behaved,in the same manner.

In the experiments which have been described thus far, the fibrin substrate was prepared by the addition of bovine thrombin to human or bovine fibrinogen. Data were obtained to determine the effect of streptokinase-activated enzyme on fibrin formed during "spontaneous" clotting of human plasma.

Aliquots of $0.3 \mathrm{ml}$. of native platelet-deficient human plasma were pipetted in duplicate into pyrex tubes containing $0.1 \mathrm{ml}$. of a solution of streptokinase $(2,500$ units per $\mathrm{ml}$.) and into silicone-lined tubes. The clotting times and clot lysis times were then determined at $37^{\circ} \mathrm{C}$.

Human platelet-deficient plasma clotted in glass tubes at $37^{\circ} \mathrm{C}$. much more rapidly than in silicone tubes (Table IV). When such plasma was mixed with streptokinase, the clots which formed in glass tubes dissolved completely before clots appeared in the silicone-lined tubes. The clots which formed in the silicone-lined tubes then lysed after an interval approximately the same as that of the clots in glass tubes. In other words, under the conditions of this experiment, fibrin formed during spontaneous clotting of human plasma was liquefied in a 
TABLE IV

The effect of surface on clotting and fibrinolysis in platelet-deficient plasma

Clotting time (min.) and clot lysis time (min.) of a mixture of $0.1 \mathrm{ml}$. streptokinase $(2,500$ units $/ \mathrm{ml}$.), and $0.3 \mathrm{ml}$. of native platelet-deficient human plasma in pyrex and silicone-coated tubes (internal diameter $11 \mathrm{~mm}$.).

The Clot Lysis Time was measured from the time the reagents were mixed.

\begin{tabular}{ccc}
\hline $\begin{array}{c}\text { Nature of } \\
\text { surface }\end{array}$ & $\begin{array}{c}\text { Clotting } \\
\text { time } \\
\text { (min.) }\end{array}$ & $\begin{array}{c}\text { Clot lysis } \\
\text { time } \\
\text { (min.) }\end{array}$ \\
\hline Glass & 4.5 & 8 \\
Silicone & 9 & 15 \\
\hline
\end{tabular}

shorter time than was required for the destruction of fibrinogen.

Another possibility which required examination was that it was easier for streptokinase to activate the proteolytic enzyme in human serum than in plasma. To test this, streptokinase was added to a mixture of oxalated human serum and bovine fibrinogen, and the time required for the digestion of fibrinogen and fibrin was determined immediately (Table V). Again appreciable quantities of fibrinogen remained at a time when all visible fibrin disappeared. When either plasma or serum mixed with fibrinogen was diluted with buffer, and optimal amounts of streptokinase were added, the proteolytic enzyme was activated whether or not the fibrinogen had been clotted by thrombin.

\section{(3) The time required for the spontaneous diges- tion of fibrinogen and fibrin in oxalated plasma}

Fantl and Simon (2) reported that the clotted plasma of patients who had been given electric shock therapy underwent fibrinolysis before appreciable digestion of fibrinogen was noted. If this were the case, then one might infer that the spontaneous activation of the plasma proteolytic

\section{TABLE V}

The relative effect of streptokinase upon the digestion of fibrinogen and fibrin in human serum

Time required for digestion of (a) fibrin, in a mixture of $0.1 \mathrm{ml}$. bovine thrombin (10 N.I.H. units $/ \mathrm{ml}$.), $0.1 \mathrm{ml}$. streptokinase $(2,500$ units $/ \mathrm{ml}$.), and $0.3 \mathrm{ml}$. oxalated serum, and (b) fibrinogen, in this same mixture, with $0.1 \mathrm{ml}$. buffer substituted for thrombin. Desiccated fibrinogen was dissolved in the oxalated serum in a concentration of $300 \mathrm{mg}$. per $100 \mathrm{ml}$.

\begin{tabular}{lc}
\hline \hline Substrate & Time for digestion in minutes \\
\hline Fibrin & 2.6 \\
Fibrinogen & 6.5
\end{tabular}

enzyme in incubated plasma was accelerated by the process of clotting. To test this, the time required for clot lysis and for the digestion of fibrinogen in human plasma were compared. Blood was obtained from patients with Laennec's cirrhosis, and from normal individuals. In previous studies it had been demonstrated that the lysis time of recalcified plasma clots was less than three days in most patients with cirrhosis, and three days or more in normal individuals (15). Aliquots of $0.5 \mathrm{ml}$. of plasma were pipetted into each of a series of pyrex tubes (internal diameter $11 \mathrm{~mm}$.). The plasma in the first tube was clotted by the addition of 0.1 ml. of thrombin solution containing $10 \mathrm{~N}$. I. H. units per $\mathrm{ml}$. Clotting was induced by the addition of thrombin rather than by recalcification, since there is evidence that calcium ions accelerate the activation of the enzyme (8). The clotted and unclotted tubes of plasma were then incubated at $37^{\circ} \mathrm{C}$. At intervals of one or two days, the unclotted tubes were tested for the presence of undigested fibrinogen by the addition of $0.1 \mathrm{ml}$. of thrombin $(1,000 \mathrm{~N}$. I. H. units per ml.). When no clot was formed after the addition of this large amount of thrombin, it was assumed that all of the coagulable fibrinogen had been digested. Large amounts of thrombin were used since the fibrinogen appeared to grow less reactive to thrombin as incubation proceeded.

In 14 normal individuals, the lysis time of clots formed by the addition of thrombin to oxalated plasma varied from three to nine days. In all except one subject, no fibrinogen was detectable in the unclotted tubes on the day when all the fibrin had been digested. In the fourteenth subject, fibrinolysis was complete in five days, but fibrinogen did not disappear until the sixth day.

The same experiment was performed with the plasma of 10 patients in whom there was clinical and laboratory evidence of Laennec's cirrhosis. In seven of the patients fibrinolysis was complete in less than three days; the clot lysis time of the other three patients was three days or longer. In six instances, fibrinogen was still detectable in the tubes of unclotted plasma, either at the time that all the fibrin had disappeared or as long as five days later. In the other four patients, no fibrinogen was detectable in the unclotted tubes on the day when all the fibrin had been digested. Thus, in some patients with cirrhosis, as in Fantl's pa- 
tients undergoing electro-shock therapy, the clotting process may have activated the proteolytic enzyme in plasma, a phenomenon not usually observed in normal individuals.

\section{DISCUSSION}

The length of time required for the plasma proteolytic enzyme to liquefy fibrin has been compared with the length of time required to digest fibrinogen to the point at which it is incoagulable. The various experiments which have been described would appear to reconcile the contradictory reports of Christensen (1) and of Fantl and his associates $(2,3)$. The digestion of both fibrinogen and fibrin by the plasma proteolytic enzyme results principally in the breakdown of the molecule whose molecular weight is approximately 400,000 to 700,000 to molecules whose molecular weight is approximately 100,000 (7). At the same time, the fibrin liquefies, and presumably the fibrinogen becomes incoagulable. Plasma proteolytic enzyme, which had been activated either by chloroform (Table I) or by a combination of chloroform and streptokinase (Table III) liquefied fibrin and rendered fibrinogen incoagulable in approximately the same time. This suggests that the active enzyme digests fibrinogen and fibrin at the same rate, as claimed by Christensen (1). On the other hand, when streptokinase was mixed with human plasma, fibrin was liquefied before fibrinogen was rendered incoagulable, as claimed by Fantl and Fitzpatrick (3). When streptokinase is added to plasma, at least two consecutive reactions occur $(1,4)$. First, the streptokinase activates the plasma proteolytic enzyme from its precursor, and, second, the active enzyme then digests available substrates. In the present experiments, when streptokinase was added to unclotted plasma, the activated enzyme digested fibrinogen relatively slowly. When this mixture of streptokinase and plasma clotted, either spontaneously, or upon the addition of thrombin, the fibrin which formed from the fibrinogen was then digested rapidly. Since active plasma proteolytic enzyme appeared to digest fibrinogen and fibrin at equal rates, one may conclude that activation of the plasma enzyme by streptokinase was accelerated by the change which occurred when fibrinogen was converted to fibrin.

One explanation for the effect of clotting in these experiments is that the chemical differences between plasma and serum permitted more ready activation of the precursor of the protease in serum. However, it was not possible to demonstrate that there was a difference in the reactivity of the precursor in plasma and serum. When fibrinogen was added to oxalated serum, fibrin was again more readily digested than fibrinogen when streptokinase was added (Table V). This suggests that it is the process of clot formation or the presence of the clot which accelerates the action of streptokinase, and not a chemical difference between plasma and serum. The experiments reported do not furnish information as to the role of clot formation in the activation of the plasma protease. Perhaps the fibrin clot furnishes a surface favorable to the activation of the plasma proteolytic enzyme by streptokinase. However, attempts to increase the rate of activation by the use of other adsorbents such as kaolin were unsuccessful. These experiments do not exclude the possibility that the fibrinogen added to the serum restored some inhibitor removed during coagulation.

Fantl and Simon (2) also reported that fibrin was more readily digested than fibrinogen by the proteolytic enzyme which became spontaneously active when plasma was incubated at $37^{\circ} \mathrm{C}$. The data which have been presented suggest that this was true in the plasma of some patients with Laennec's cirrhosis who had rapid clot lysis times. But in normal individuals whose plasma clots did not lyse in less than three days, the times required for fibrinolysis and for the digestion of fibrinogen to the point at which it was incoagulable were usually similar. The mechanism of rapid fibrinolysis in diseased states is not understood. Perhaps an abnormal kinase was present in the plasma of the patients with cirrhosis, and the effect of this kinase was increased by the clotting process. Earlier experiments suggested that the rate of fibrinolysis was correlated with the rate in which the inhibitor in plasma against its proteolytic enzyme deteriorated (16). These two hypotheses are not mutually exclusive.

The report of Johnson and Tillett (17) lends significance to these experiments. These authors observed that the intravenous injection of streptokinase was followed by lysis of intravascular thrombi in laboratory animals. The experiments described in the present report suggest that the 
intravenous injection of streptokinase might result in the preferential digestion of fibrin over fibrinogen. Interestingly, Johnson and Tillett observed relatively little change in the concentration of fibrinogen in animals injected with sufficient streptokinase to lyse the experimental thrombi. The process of activation of the plasma proteolytic enzyme is most complex and one should hesitate to draw too close an analogy between data obtained in vivo and in vitro.

\section{SUM MARY}

1. No appreciable difference was observed between the time required for the liquefaction of fibrin and for rendering fibrinogen incoagulable by active bovine or human plasma proteolytic enzyme.

2. When streptokinase was mixed with oxalated or native human plasma, it took a shorter time for fibrin to be dissolved than for fibrinogen to become incoagulable.

3. In the plasma of some patients with cirrhosis, "spontaneous" fibrinolysis occurred more rapidly than fibrinogenolysis. In the plasma of most normal individuals, and of other patients with cirrhosis, no difference was noted in the time required for the liquefaction of fibrin and the digestion of fibrinogen.

4. These experiments suggest that the activation of plasma proteolytic enzyme, either spontaneously or by streptokinase, may be accelerated by the process of coagulation.

\section{REFERENCES}

1. Christensen, L. R., Streptococcal fibrinolysis: a proteolytic reaction to a serum enzyme activated by streptococcal fibrinolysin. J. Gen. Physiol., 1945, 28, 363.

2. Fantl, P., and Simon, S. E., Fibrinolysis following electrically induced convulsions. Australian J. Exper. Biol. \& M. Sc., 1948, 26, 521.

3. Fantl, $P$., and Fitzpatrick, M., Fibrinolysis induced by brain extracts. Brit. J. Exper. Path., 1950, 31, 131.

4. Kaplan, M. H., Nature and role of the lytic factor in hemolytic streptococcal fibrinolysis. Proc. Soc. Exper. Biol. \& Med., 1944, 57, 40.
5. Christensen, L. R., and MacLeod, C. M., A proteolytic enzyme of serum: characterization, activation, and reaction with inhibitors. J. Gen. Physiol., 1945, 28, 559.

6. Loomis, E. C., George, C., Jr., and Ryder, A., Fibrinolysis: nomenclature, unit, assay, preparation and properties. Arch. Biochem., 1947, 12, 1.

7. Holmberg, C. G., Studies on the splitting of fibrin under the influence of fibrinolysin from haemolytic streptococci. Ark. Kemi, Minerol. och Geol., 1944, 17A, No. 28.

8. Ratnoff, O. D., Studies on a proteolytic enzyme in human plasma. VIII. The effect of calcium and strontium ions on the activation of the plasma proteolytic enzyme. J. Exper. Med., 1952, 96, 319.

9. Ware, A. G., Guest, M. M., and Seegers, W. H., Fibrinogen with special reference to its preparation and certain properties of the product. Arch. Biochem., 1947, 13, 231.

10. Seegers, W. H., and Smith, H. P., Factors which influence the activity of purified thrombin. Am. J. Physiol., 1942, 137, 348.

11. Christensen, L. R., Methods for measuring the activity of the components of the streptococcal fibrinolytic system, and streptococcal desoxyribonuclease. J. Clin. Invest., 1949, 28, 163.

12. Conley, C. L., Hartmann, R. C., and Morse, W. I., II, The clotting behavior of human "platelet-free" plasma: evidence for the existence of a "plasma thromboplastin." J. Clin. Invest., 1949, 28, 340.

13. Hartman, R. C., Conley, C. L., and Lalley, J. S., Studies on the initiation of blood coagulation. I. The relationship of platelets to the clot-promoting effect of glass surfaces. Bull. J. Hopkins Hosp., 1949, 85, 231.

14. Pinniger, J. L., and Prunty, F. T. G., Some observations on the blood-clotting mechanism. The role of fibrinogen and platelets, with reference to a case of congenital afibrinogenemia. Brit. J. Exper. Path., 1946, 27, 200.

15. Ratnoff, O. D., Studies on a proteolytic enzyme in human plasma. IV. The rate of lysis of plasma clots in normal and diseased individuals, with particular reference to hepatic disease. Bull. J. Hopkins Hosp., 1949, 84, 29.

16. Ratnoff, O. D., Studies on a proteolytic enzyme in human plasma. III. Some factors controlling the rate of fibrinolysis. J. Exper. Med., 1948, 88, 401.

17. Johnson, A. J., and Tillett, W. S., The lysis in rabbits of intravascular blood clots by the streptococcal fibrinolytic system (streptokinase). J. Exper. Med., 1952, 95, 449. 